\title{
Retrospective Analysis of Doxycycline or Bactrim Prophylaxis for Patients with Chronic Obstructive Pulmonary Disease
}

\author{
Erik Johnson, Khushboo Verma and Sudhir Sekhsaria* \\ Department of Asthma, Allergy and Sinus Center, Medstar Union Memorial Hospital, USA
}

Submission: July 02, 2019; Published: August 05, 2019

*Corresponding author: Sudhir Sekhsaria, Department of Allergy and Sinus Center, Medstar Union Memorial Hospital Baltimore, USA

\begin{abstract}
Background: Azithromycin prophylaxis has shown to decrease COPD exacerbations but led to hearing deficits. Therefore, there is a need to study other antibiotics as possible prophylaxis for COPD exacerbations.

Objective: To evaluate the effectiveness of doxycycline or Bactrim prophylaxis for patients with moderate to severe COPD.

Methods: We studied patients with moderate to severe COPD who were treated with prophylactic doxycycline or Bactrim in the fall and winter months along with their standard COPD therapy. From patient histories, we determined the number of exacerbations/year and hospitalizations/year prior to and after prophylaxis. Paired t-tests were used to analyze the data.

Results: 17 patients with moderate to severe COPD on standard therapy were identified. Prophylactic doxycycline or Bactrim were added to their treatment regimens as a part of routine prophylaxis. Patients were on prophylaxis for a period of 6 months per year. The number of average exacerbations per year decreased from $4.44 \pm 4.42$ to $1.20 \pm 1.0(n=15, p=0.0047)$ and the number of hospitalizations per year decreased from $1.75 \pm 1.12$ to $0.00 \pm 0$ ( $n=5, p=0.0125)$. The number of exacerbations per person during the months with prophylaxis was 1.19 compared with 1.63 exacerbations per person during the months without prophylaxis $(n=16, p=0.24)$. The antibiotics were well tolerated.

Conclusion: This retrospective analysis showed a significant decrease in the number of exacerbations and hospitalizations per year for COPD patients undergoing doxycycline or Bactrim prophylaxis. This small study suggests the need for a prospective randomized study evaluating prophylactic doxycycline, Bactrim or other antibiotics in patients with moderate to severe COPD.
\end{abstract}

Keywords: COPD; Bactrim; Doxycycline; Antibiotic prophylaxis

Abbreviations: COPD: Chronic Obstructive Pulmonary Disease; SMX-TMP: Sulfamethoxazole and Trimethoprim; CGD: Chronic Granulomatous Disease; GOLD: Global Initiative for Chronic Obstructive Lung Disease

\section{Introduction}

Chronic Obstructive Pulmonary Disease (COPD) has become a worldwide epidemic and continues to be one of the leading causes of morbidity and mortality [1-3]. It is expected to be the third most common cause of death worldwide by 2020 [2]. In 2000, patients with COPD accounted for 8 million physician office and hospital outpatient visits, 1.5 million emergency department visits, 726,000 hospitalizations, and 119,000 deaths [3]. In 2016, the Global Burden of Disease Study reported the prevalence of COPD as 251 million cases. All these lead to increased costs at the individual and societal levels. Frequent exacerbations are associated with a reduced quality of life and possibly with increased depression and anxiety [4,5]. Many COPD exacerbations are due to secondary bacterial infections over viral infections and therefore, preventative treatments with antibiotics may help improve quality of life of patients, reduce the number of exacerbations and reduce health care costs [6]. It is reported that there is almost a two-fold increase in COPD exacerbations during the winter months [7].

Despite the availability of effective macrolide prophylaxis, the potential side effects of these antibiotics limit their longterm use. Therefore, antibiotics like doxycycline and Bactrim can be considered viable alternatives for prophylaxis against COPD exacerbations. Doxycycline, a tetracycline antibiotic, has been shown to possess anti-inflammatory properties in addition to its antibiotic properties, which could explain its potential effectiveness for chronic inflammatory diseases such as COPD [8]. Furthermore, it has been shown to accumulate in the sputum during its use, which may prevent the colonization of 
bacteria and the recurrence of acute infections [9]. More recent studies have shown that doxycycline decreases the production of Interleukin-8, which is an inflammatory cytokine [10]. Bactrim, is a combination of Sulfamethoxazole and Trimethoprim (SMXTMP), has been shown to be an effective prophylactic agent in diseases such as Chronic Granulomatous Disease (CGD), whereby the number of life-threatening episodes decreased from every 10 months to every 40 months when put on prophylaxis [11]. It has also been proven effective as prophylactic treatment for interstitial pneumonia [12].

Because there is little research regarding the potential effectiveness of different antibiotics with regards to COPD prophylaxis, this study focuses on the effectiveness of doxycycline and Bactrim as potential prophylactic agents.

\section{Materials and Methods}

We conducted a retrospective study to determine effectiveness of alternative antibiotics for COPD prophylaxis. We used patient records to collect all the information needed. We included chronic COPD patients, falling in the moderate to severe categories as per the Global initiative for chronic Obstructive Lung Disease (GOLD) guidelines, with a smoking history of a minimum of 20 pack years, already on the standard COPD therapy prior to the introduction of antibiotic prophylaxis and who received doxycycline or Bactrim prophylaxis for only 6 months in a year. We excluded patients with co-existing lung diseases (none of our patients had asthma), patients on yearlong antibiotic prophylaxis. The patients included represented both genders equally. From the patient histories, the following

Results

Table 1: Demographic Information for Patients in the Analysis.

\begin{tabular}{|c|c|}
\hline \multirow{2}{*}{$\begin{array}{l}\text { Number of Patients } \\
\text { a) Doxycycline prophylaxis } \\
\text { b) Bactrim prophylaxis }\end{array}$} & $\begin{array}{l}\mathbf{n}=\mathbf{1 7} \\
\mathrm{n}=15\end{array}$ \\
\hline & $\mathrm{n}=2$ \\
\hline Number of Patients with hospitalization records & $\mathrm{n}=5$ (all doxycycline) \\
\hline Male: Female & $8: 9$ \\
\hline Average Age (Range) & 70.7 years old $(58: 80)$ \\
\hline $\begin{array}{l}\text { Median } \text { FEV }_{\mathbf{1}} \text { \% predicted for all patients (Range) } \\
\text { a) \# Patients with median FEV1 \% predicted } \geq 50 \% \text { (MODERATE) } \\
\text { b) \# Patients with median FEV1 \% predicted between 30-50\% (SEVERE) } \\
\text { c) \# Patients with median FEV1 \% predicted } \leq 30 \% \text { (VERY SEVERE) }\end{array}$ & $\begin{array}{l}\text { 37.04\% (16.33:60.88) } \\
n=2 \\
n=11 \\
n=4\end{array}$ \\
\hline Patients with Standard COPD Treatments during Prophylaxis: & \\
\hline \multirow{2}{*}{$\begin{array}{l}\text { i. ICS, LABA, and LAMA } \\
\text { a) With oxygen treatment } \\
\text { b) With theophylline treatment } \\
\text { With oxygen and theophylline treatments } \\
\text { ii. ICS and LABA } \\
\text { a) With oxygen treatment } \\
\text { b) With theophylline treatment }\end{array}$} & $\begin{array}{l}\mathbf{n}=\mathbf{1 5} \\
\mathrm{n}=6 \\
\mathrm{n}=4 \\
\mathrm{n}=1\end{array}$ \\
\hline & $\begin{array}{l}\mathbf{n}=2 \\
\mathrm{n}=1 \\
\mathrm{n}=0\end{array}$ \\
\hline
\end{tabular}

ICS: Inhaled Corticosteroids; LABA: Long-Acting Beta Agonist: LAMA: Long-Acting Muscarinic Antago

17 patients qualified for the study, with fifteen patients on doxycycline prophylaxis and two on Bactrim prophylaxis.

Patients were on prophylaxis for 6 months/year for a 3-year period. The demographic data for the patients with average 
values for age, FEV1 \% predicted and duration of prophylaxis are reported in Table 1. Most patients were treated with a standard COPD therapy, which consists of inhaled corticosteroids, longacting beta-agonists and long-acting muscarinic antagonists. However, two of the patients were treated without the longacting muscarinic agonists. Both antibiotics were tolerated well except for some nausea in thse first few days of doxycycline treatment. As the prophylactic dose of doxycycline is only half its therapeutic dose, all the patients reported resolution of nausea after the first few days.

The number of average exacerbations per year decreased from $4.44 \pm 4.42$ to $1.20 \pm 1.0(n=15, p=0.0034)$ before prophylaxis and after the start of prophylaxis respectively (Figure 1). The number of hospitalizations/years decreased from $1.75 \pm 1.12$ to $0.00 \pm 0(n=5, p=0.0125)$ before prophylaxis and after the start of prophylaxis, respectively (Figure 1). None of the patients had reported hospitalizations after they started the prophylaxis.

The number of exacerbations/people during the months of prophylaxis was $1.19 \pm 1.33$ compared with $1.63 \pm 2.03$ exacerbations/person during the months off prophylaxis $(n=16$, $p=0.24)$. One patient was excluded from this analysis because she was on yearlong Bactrim prophylaxis.

\section{Discussion}

Macrolide antibiotics, specifically azithromycin and erythromycin, have been shown to decrease the frequency of exacerbations and to improve the quality of life for patients with COPD [6,13]. Albert et al. [6] designed a prospective study, in which subjects received either $250 \mathrm{mg}$ azithromycin or placebo daily. Subjects taking azithromycin had fewer acute exacerbations than those in the placebo group and the median time to the first acute exacerbation was significantly longer. However, adverse side effects such as hearing deficits from longterm use of azithromycin were reported in a significant number of patients [6].

We used a retrospective study design, so we did not use a placebo, instead, we did comparative studies on patients while on and off prophylactic antibiotics. We chose to administer antibiotics for a 6-month period during the fall and winter months (in contrast to previous studies in which patients were administered antibiotics all year long) since that is when most exacerbations tend to occur [14].

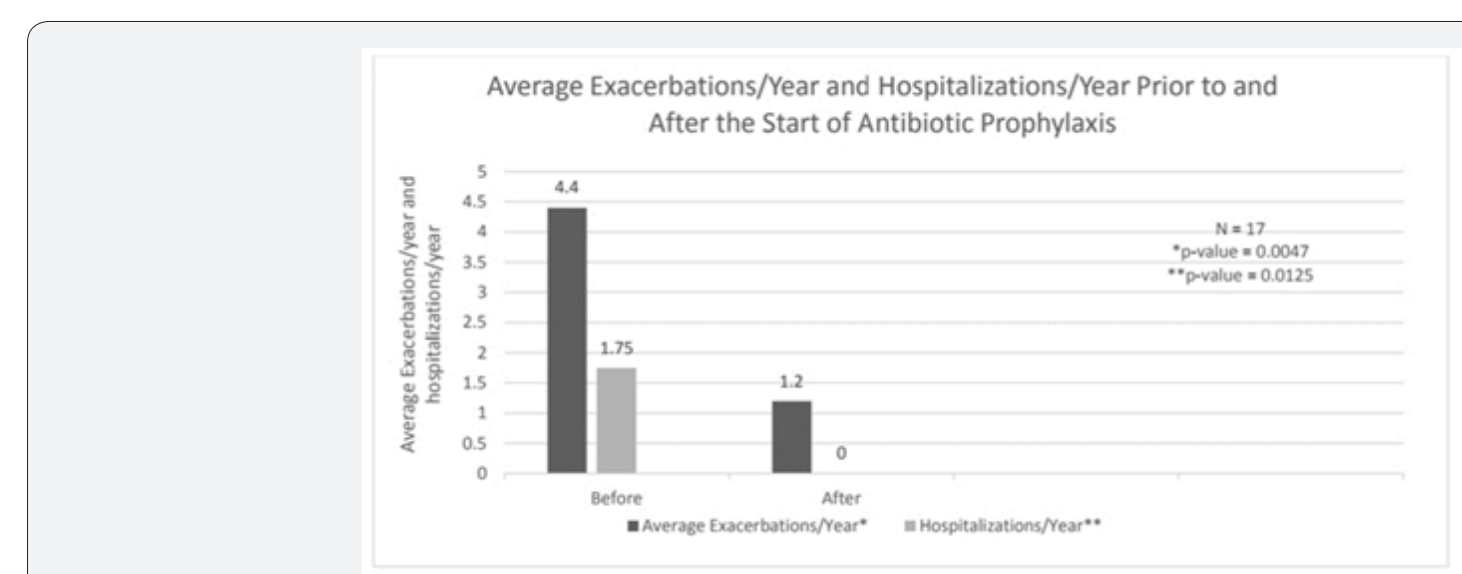

Figure 1: Bar graphs depicting exacerbations/year and hospitalizations/year prior to and after antibiotic prophylaxis.

We found that there was a statistically significant reduction in the number of exacerbations and hospitalizations after the start of prophylaxis with doxycycline or Bactrim for patients with moderate to severe COPD (Figure 1). Doxycycline and Bactrim were tolerated well except for a few cases of mild nausea in the initial days of treatment with doxycycline. However, our small study failed to reach statistical significance for the number of exacerbations and hospitalizations comparing the months on prophylaxis with the months without prophylaxis. With a larger study, the results may show a significant reduction of exacerbations per person during the months when prophylaxis was taken. This approach of using antibiotics for 6 months a year instead of yearlong antibiotics may minimize their potential side effects.

Our study is limited by the small number of study subjects as exacerbations are often not reported to physicians [15]. Not reporting certain exacerbations could skew the significance of the data in either direction. Nevertheless, the data reported is very significant for a small study and supports further studies.

\section{Conclusion}

In summary, we retrospectively analyzed the effectiveness of antibiotics doxycycline and Bactrim as prophylactic agents for patients with moderate to severe COPD. From the analysis, these antibiotics significantly reduced the number of exacerbations/ year and hospitalizations/year. This data supports the need for a larger, prospective and well-controlled study that can adequately assess the effectiveness of doxycycline or Bactrim prophylaxis as alternatives to macrolides, in patients with moderate to severe COPD. There is a need for studies to determine the effectiveness of antibiotic prophylaxis specifically in the fall and winter months well as its retrospective nature. Furthermore, COPD 
versus a yearlong prophylaxis, to compare risks and benefits of half-yearly prophylaxis as compared to yearlong prophylaxis.

\section{Acknowledgments}

We would like to thank Medstar for funding the research. We would like to thank Georgetown School of Medicine for organizing the research. We also want to thank the staff of the Asthma, Allergy and Sinus Centers at Medstar Union Memorial Hospital, White Marsh, Rockville and Waldorf.

\section{References}

1. Mannino DM, Buist AS (2007) Global burden of COPD: risk factors, prevalence, and future trends. Lancet 370(9589): 765-773.

2. Chapman KR, Mannino DM, Soriano JB, Vermeire PA, Buist AS, et al. (2006) Epidemiology and costs of chronic obstructive pulmonary disease. Eur Respir J 27(1): 188-207.

3. Mannino DM, Homa DM, Akinbami LJ, Ford ES, Redd SC (2002) Chronic obstructive pulmonary disease surveillance--United States, 19712000. MMWR Surveill Summ 51(6): 1-16.

4. Seemungal TA, Donaldson GC, Paul EA, Bestall JC, Jeffries DJ, et al. (1998) Effect of exacerbation on quality of life in patients with chronic obstructive pulmonary disease. Am J Respir Crit Care Med 157(5 Pt 1): 1418-1422.

5. Okubadejo AA, Paul EA, Jones PW, Wedzicha JA (1996) Does longterm oxygen therapy affect quality of life in patients with chronic obstructive pulmonary disease and severe hypoxemia? Eur Respir J 9(11): 2335-2339.

6. Albert RK, Connett J, Bailey WC, Casaburi R, Cooper Jr JA, et al. (2011) Azithromycin for prevention of exacerbations of COPD. N Engl J Med 365(8): 689-698.
7. Jenkins CR, Celli B, Anderson JA, Ferguson GT, Jones PW, et al. (2012) Seasonality and determinants of moderate and severe COPD exacerbations in the TORCH study. Eur Respir J 39(1): 38-45.

8. Krakauer T, Buckley M (2003) Doxycycline is anti-inflammatory and inhibits staphylococcal exotoxin-induced cytokines and chemokines. Antimicrob Agents \& Chemother 47(11): 3630-3633.

9. Hartnett BJ, Marlin GE (1976) Doxycycline in serum and bronchial secretions. Thorax 31(2): 144-148.

10. Hoyt JC, Ballering JG, Hayden JM, Robbins RA (2013) Doxycycline Decreases Production of Interleukin-8 in A549 Human Lung Epithelial Cells. Southwest J Pulm \& Crit Care 6(3): 130-142.

11. Margolis DM, Melnick DA, Alling DW, Gallin JI (1990) Trimethoprimsulfamethoxazole prophylaxis in the management of chronic granulomatous disease. J Infect Dis 162(3): 723-726.

12. Enomoto T, Azuma A, Matsumoto A, Nei T, Fujita K, et al. (2008) Preventive effect of sulfamethoxazole-trimethoprim on Pneumocystis jiroveci pneumonia in patients with interstitial pneumonia. Intern Med 47(1): $15-20$

13. Seemungal TA, Wilkinson TM, Hurst JR, Perera WR, Sapsford RJ, et al. (2008) Long-term erythromycin therapy is associated with decreased chronic obstructive pulmonary disease exacerbations. Am J Respir Crit Care Med 178(11): 1139-1147.

14. Donaldson GC, Warzecha JA (2014) The causes and consequences of seasonal variation in COPD exacerbations. Int J Chron Obstruct Pulmon Dis 9: 1101-1110.

15. Xu W, Collet JP, Shapiro S, Lin Y, Yang T, et al. (2010) Negative impacts of unreported COPD exacerbations on health-related quality of life at 1 year. Eur Respir J 35(5): 1022-1030.

\section{Your next submission with Juniper Publishers} will reach you the below assets

- Quality Editorial service

- Swift Peer Review

- Reprints availability

- E-prints Service

- Manuscript Podcast for convenient understanding

- Global attainment for your research

- Manuscript accessibility in different formats ( Pdf, E-pub, Full Text, Audio)

- Unceasing customer service

Track the below URL for one-step submission https://juniperpublishers.com/online-submission.php 